\title{
THE EFFECT OF A COMPLEX STRESS STATE ON FATIGUE CRACK PROPAGATION AND THE ORIENTATION OF THE CRACKING PLANE IN VT3-1 AERONAUTICAL TITANIUM ALLOY
}

\author{
Dorota Kocańda, Janusz Mierzyński \\ Military University of Technology \\ Warsaw, Poland
}

\begin{abstract}
The subject of the paper is the investigations of fatigue crack imitation and propagation in notched specimens made of the VT3-1 aeronautical russian titanium alloy under combined bending-torsion loading. The presence of short cracks was revealed at various ratios of bending to torsion. Experimental courses of short and long crack growth rates have been proved by the SEM and TEM micrographs which illustrated the changes in the mechanism of cracking in the examined specimens. The attempt was undertaken in order to explain partly brittle fracture that was observed in the range of fatigue short crack growth in the VT3-1 titanium alloy specimens. The results of the study of atmospheric hydrogen absorption capability and its ability for penetration inside the faces of nucleated and propagated microcracks in the surface layer allowed for suggestion that the cleavage mechanism of fracture found in the regime of short crack growth in the VT3-1 titanium alloy specimens was induced by hydrogen.
\end{abstract}

\section{INTRODUCTION}

The results of titanium alloy fatigue crack tests have been published for many years. It is connected with the wide use of titanium alloys in structures, in which there is needed a high ratio of material strength to a component's weight. Selected publications on the above mentioned subject are included in Reference [1], which refers to 41 works.

Titanium alloys show a wide diversity of fatigue properties, which results from the diversity in their chemical composition and structure. Production technology as well as the type and conditions of heat treatment play a great role in attaining suitable mechanical and fatigue properties of the alloys. The size of grains in titanium alloys shows exceptionally high range, namely from 5 to $1000 \mu \mathrm{m}$. They have a significant effect on the propagation of cracks, especially short ones, owing to crack arrest effects at grain boundaries. There are different crack initiation mechanisms in $\alpha$ phase (a hexagonal system) and $\beta$-phase (a body-centered cubic system), which the VT3-1 titanium alloy consists of [2]. Generally speaking, getting knowledge of the crack growth rate in multicomponent titanium alloys requires familiarizing oneself with specific publications, since it is difficult to formulate any general conclusions.

In the study, a significant amount of attention was given to the propagation of short fatigue cracks in the VT3-1 alloy. The term "short cracks" indicates cracks which propagate at the initial stage of fatigue changes in a structural material. Earlier research on short cracks in the 45 steel was

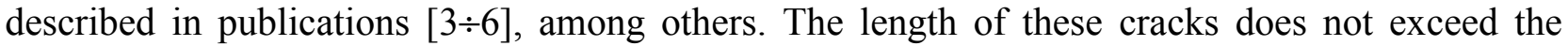
threshold length $l_{t h}$ which is conditioned by the size of material grains. Short cracks propagate below the threshold value of the stress intensity factor $K_{t h}$. Above these threshold values, there propagate long cracks, the growth of which has to be controlled during the operating period of 
a structural component, since they may cause the complete destruction of a component. Therefore, the range of short crack propagation constitutes the safe operating period of components.

In the paper, particular emphasis was placed on indication short fatigue cracks in the VT3 - 1 alloy, determining the effect of load conditions on the change of the orientation of cracking plane as well as the correlation of the features of crack growth behaviour with the features of the microstructure of fracture surfaces. Detailed results of the research were presented for the ratios of the torsional moment $M_{t}$ to the bending moment $M_{b}$ such as $M_{t} / M_{b}=2.25$, $\mathrm{M}_{\mathrm{t}} / \mathrm{M}_{\mathrm{b}}=1$ and $\mathrm{M}_{\mathrm{t}} / \mathrm{M}_{\mathrm{b}}=0.5$. It was crucial to determine the fatigue strength range, in which short cracks propagate, as well as the range of the lengths of short cracks, which is of great importance in formulating deterministic and probabilistic descriptions of the dynamics of fatigue cracking of components. The aim was to get a complete picture of fatigue crack development.

\section{MATERIAL, SPECIMENS, RESEARCH METHODOLOGY}

Tests were conducted on specimens made of the Russian titanium alloy VT3-1. The material was forged from a bar, which was $40 \mathrm{~mm}$ in diameter, into a $20 \mathrm{~mm}$ thick flat bar. Next, it was subject to isothermal annealing, which involved heating at the temperature of $870 \div 890^{\circ} \mathrm{C}$ for two hours, cooling down in a kiln till it reached the temperature of $650^{\circ} \mathrm{C}$, keeping it in the aforementioned conditions for two hours and, finally, cooling it down in the air. Protective atmospheres were not employed in heat treatment. The correctness of the technological process was verified by examining selected mechanical properties as well as the micro- and macrostructure of bars, in accordance with the technical acceptance conditions for aeronautical industry. A material of lamellar structure was obtained as a result of the technological processes that were implemented. The structure consisted of the colonies of $\alpha$-phase lamellas, which were multidirectionally oriented, within the area of $\beta$-phase initial grains (see Fig. 2). The average width of $\alpha$-phase lamellas was estimated at $2 \div 5 \mu \mathrm{m}$, whereas their lengths showed great diversity and ran from several to a few dozen micrometers. The surface fraction of $\alpha$-phase in the structure of the VT3-1 alloy was in the range of $72.5 \%$ to $79.5 \%$. The mechanical properties of the material were as follows: $\mathrm{S}_{\mathrm{u}}=968 \mathrm{MPa}, \mathrm{S}_{0.2}=950 \mathrm{MPa}, \mathrm{E}=115.3 \mathrm{GPa}$ and elongation $12.7 \%$. Basic research was complemented by tests on specimens made from two other batches of material. The second batch of material was used in tests under a simultaneous action of torsional and bending moments with the moment ratio of $\mathrm{M}_{\mathrm{t}} / \mathrm{M}_{\mathrm{b}}=0.5$. The bars were subject to heat treatment that was identical with that of the basic batch of specimens. The share of $\alpha$-phase in the alloy structure ranged from $75.5 \%$ to $82.5 \%$. Static tensile test showed somewhat better strength properties in relation to the basic batch material, namely $\mathrm{S}_{\mathrm{u}}=974 \mathrm{MPa}, \mathrm{S}_{0.2}=966 \mathrm{MPa}$ and $\mathrm{E}=114 \mathrm{GPa}$. Tests on components loaded with the torsional moment alone were carried out on the third batch of material. Bars, the diameters of which were $25 \mathrm{~mm}$, were heated at the temperature of $900^{\circ} \mathrm{C}$ for one hour. Subsequently, they were cooled down in a kiln till they reached the temperature of $650^{\circ} \mathrm{C}$ and they were heated at that temperature for another two hours. There was obtained a finegrained equiaxial structure with the average size of $\alpha$-phase grains of $6 \div 7 \mu \mathrm{m}$. The fraction of the $\alpha$-phase ranged from $72.5 \%$ to $79.5 \%$. Mechanical properties determined for three specimens in the static tensile test were as follows: $S_{u}=1068 \div 1100 \mathrm{MPa}, S_{0.2}=980 \div 1000 \mathrm{MPa}$, elongation $15.2 \div 20 \%$ and $\mathrm{E}=115.2 \mathrm{GPa}$. Specimens with circumferential notches, the shape of which is shown in Fig. 1, were prepared for tests on the fatigue behaviour of the VT3-1 titanium alloy under complex load conditions. The stress concentration factor at the notch root is $\mathrm{K}_{\sigma}=1.34$ in the case of bending, whereas, in the case of torsion, it is equal to $K_{\tau}=1.20$. The notch zone was polished carefully and it was subject etching by a $2 \%$ solution of hydrofluoric acid in order to reveal the structure of the alloy. Each specimens loaded only under the torsion moment had circumferential notch with the radius of $\rho=4 \mathrm{~mm}$. The notches were made in the cylindrical part, 
the diameter of which was $\mathrm{D}=10 \mathrm{~mm}$. The notches were made so that the specimen diameter at the notch bottom was $d=7 \mathrm{~mm}$. In such case, the notch stress concentration factor is $\mathrm{K}_{\tau}=1,12$.

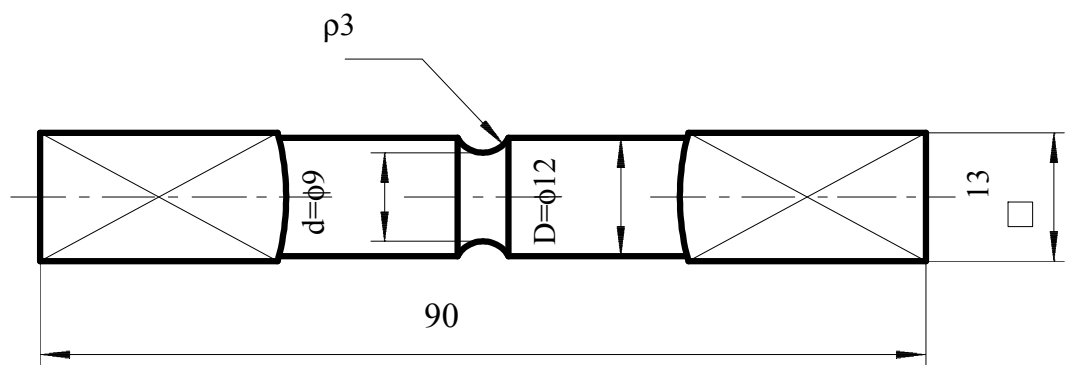

Fig.1. Fatigue test specimen geometry.

Fatigue tests were conducted with the use of a resonant strength testing machine at the frequency of load changes of $26 \mathrm{~Hz}$ and the stress ratio $\mathrm{R}=-1$. Fatigue crack growth was examined for five different load conditions:

- bending moment only,

- combined bending and torsional moments, where $\mathrm{M}_{t} / \mathrm{M}_{\mathrm{b}}=0.5$,

- combined bending and torsional moments, where $\mathrm{M}_{\mathrm{t}}=\mathrm{M}_{\mathrm{b}}$,

- combined bending and torsional moments, where $\mathrm{M}_{\mathrm{t}} / \mathrm{M}_{\mathrm{b}}=2.25$,

- torsional moment only.

Equivalent stress amplitude, $\mathrm{S}_{\mathrm{eq}}$, was calculated in accordance with the Huber-Mieses hypothesis. The limited validity of this hypothesis was taken into consideration. The hypothesis can be unreliable in the case of metals of hexagonal structure, which is characteristic of $\alpha$-phase in titanium alloy structures. However, it turned out that plastic fatigue striations are present almost in the whole fatigue zone of analysed specimens. Plastic cracking and the shallowness of the notch justifies accepting the Huber - Mieses hypothesis.

Fatigue crack growth on the notch surfaces was recorded with the use of acetylcellulose replicas by placing two replicas in the measuring area so that they covered the whole circumference of the notch bottom. On the surface of the notch root where the initiation of short cracks took place, the frequency of placing replicas was increased. Subsequently, replicas were examined with the use of a NEOPHOT-2 optical microscope, which was linked by means of a video system with a computer equipped with a program for analyzing microscopic images. Such research procedure is time-consuming and laborious, still it is one of the most precise methods used for the investigation of short fatigue cracks. The obtained results were used to produce diagrams of crack growth rates in the function of surface crack length and the cycle ratio $\mathrm{N}_{\mathrm{i}} / \mathrm{N}_{\mathrm{f}}$, where $\mathrm{N}_{\mathrm{i}}$ is the number of current cycles, $\mathrm{N}_{\mathrm{f}}$ - the number of cycles to the specimen failure.

The stress pattern and their orientation at the notch bottom in the area of maximum effort of the material for particular load conditions was determined on the basis of tensometric analyses. There was used a $45^{\circ}$ tensometric rosette produced by Vishay, with the smallest base available (the rosette washer was $2 \times 3 \mathrm{~mm}$, while each of the three rosette components was $0.38 \times 0.5 \mathrm{~mm}$ ). Test results obtained that way are attached in graphic form to the images illustrating fatigue cracks on components' surfaces (see Fig. 6, 9, 12).

The propagation of cracks into the material was investigated by analyzing the microstructure of fracture surfaces with the use of the JEM1230 transmission electron microscope. For that purpose, the acetylcellulose replicas taken from crack surfaces were sprinkled with carbon and then shadowed with platinum. 


\section{TEST RESULTS AND DISCUSSION}

\section{Loading with the bending moment}

Specimens were subjected to reversed bending in the stress amplitude range $S_{a, b}$ from 430 to $550 \mathrm{MPa}$. Elastic stresses were calculated in accordance with basic material strength equations. The elastic stress concentration factor, $\mathrm{K}_{\sigma}=1.34$, was taken into account. The investigation of surface cracks on the notch bottom was carried out with the use of the method of replicas in accordance with the methodology described in point 2. About 200 replicas were subject to analysis. It proved that, in the case of bending, there is a specific range of the propagation of short cracks and it depends on the value of stress. Cracks nucleated not only at the boundaries of $\alpha$ phase and $\beta$-phase but also in $\alpha$-phase grains. Crack growth direction varied but macroscopically it corresponded with the highest normal stress planes. This phenomenon can be observed in exemplary images in Fig. 2, which were obtained by means of an optical microscope. Specimens were tested at stresses $\mathrm{S}_{\mathrm{a}, \mathrm{b}}=544 \mathrm{MPa}$ (see Fig. 2a) and $\mathrm{S}_{\mathrm{a}, \mathrm{b}}=525 \mathrm{MPa}$ (see Fig. 2b).

The images of microstructure of fracture surfaces with symptoms of plastic deformations and quasi-brittle cracking observed under a transmission microscope is presented in Fig. 3. The images show specimens tested at $\mathrm{S}_{\mathrm{a}, \mathrm{b}}=544 \mathrm{MPa}\left(\mathrm{N}_{\mathrm{f}}=6 \cdot 10^{4}\right.$ cycles). What is particularly interesting is the fact that the aforementioned quasi-brittle cracking with signs of small plastic deformations (see Fig. 3a) turns into plastic cracking at a particular crack depth. Plastic cracking manifests itself in the form of plastic fatigue striations. A large part of the fatigue zone is covered only with striations of this type.
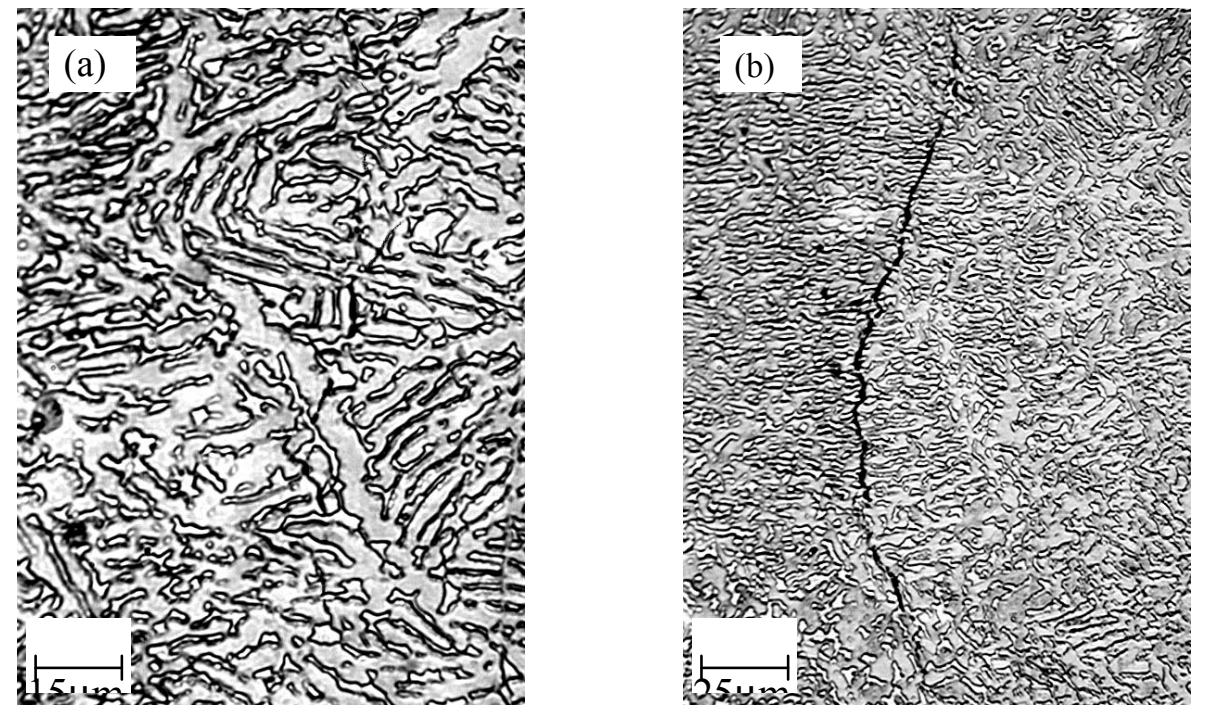

Fig. 2. Examples of short fatigue cracks in the VT3-1 titanium alloy under bending loads.

The complexity of and irregularity in the course of the crack growth is reflected in diagrams in Fig. 4. The diagrams illustrate crack lengths depending on the cycle ratio $\mathrm{N}_{\mathrm{i}} / \mathrm{N}_{\mathrm{f}}$ (Fig. 4a) as well as crack growth rates depending on crack lengths (Fig. $4 b$ ), the ratio $\mathrm{N}_{\mathrm{i}} / \mathrm{N}_{\mathrm{f}}($ Fig. $4 \mathrm{c}$ ) and the stress intensity factor $\mathrm{K}_{\max }$ (Fig. 4d). It is easy to notice an anomaly in the diagram in Fig. 4a, as the crack propagates faster at stress $\mathrm{S}_{\mathrm{a}, \mathrm{b}}=467 \mathrm{MPa}$ than at higher values of stress. The above mentioned anomaly does not manifest itself so clearly in crack growth rate diagrams in Figs $4 \mathrm{~b}-4 \mathrm{~d}$. 



Fig. 3. The microstructure of fracture surfaces in VT3-1 titanium alloy specimens subjected to bending in the zone of crack initiation (a) and in the central part of fatigue zone (b) .
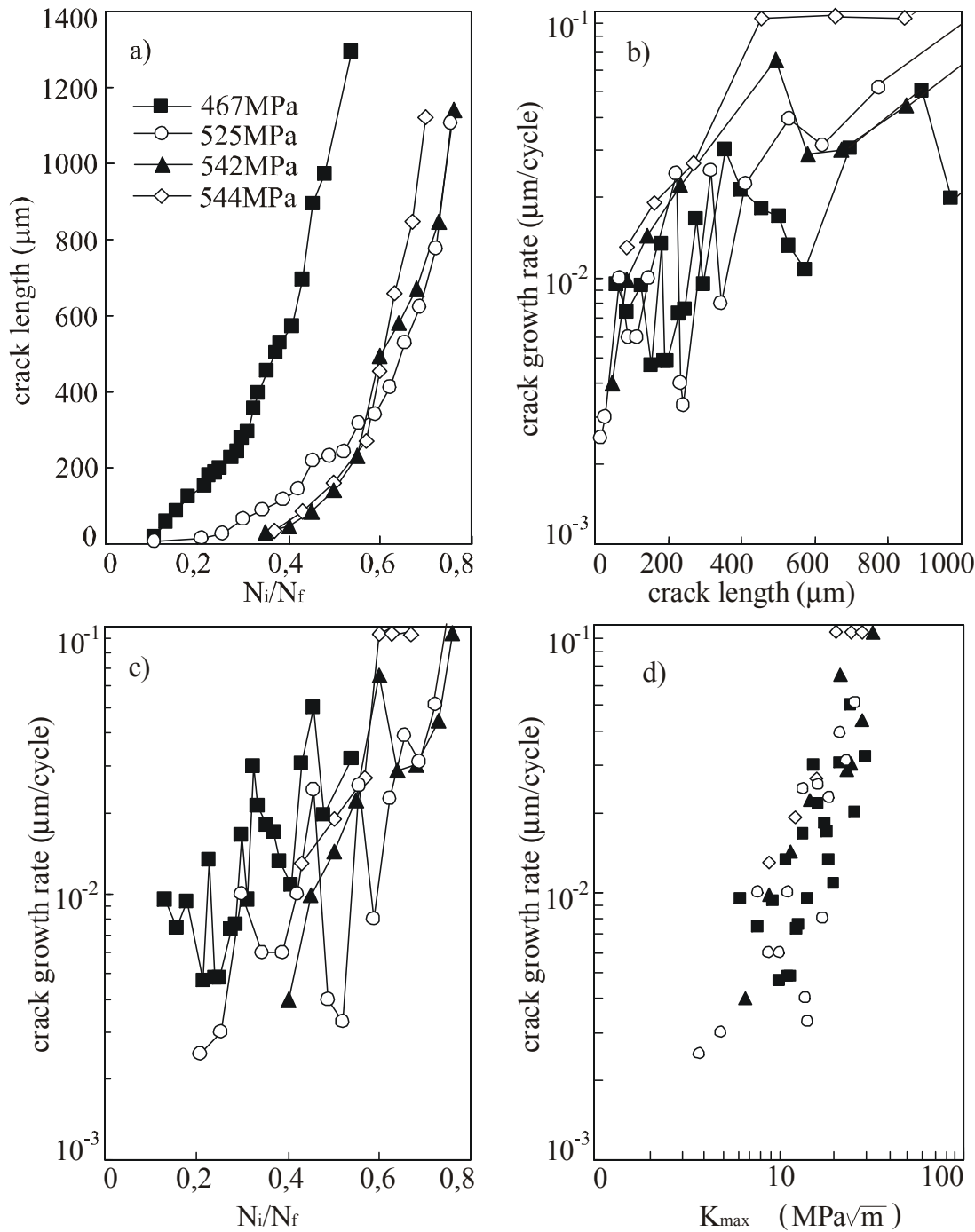

Fig. 4. Crack lengths depending on the cycle ratio $N_{i} / N_{f}$ (a); crack growth rate depending on crack lengths (b), the ratio $N_{i} / N_{f}(c)$ and the stress intensity factor $K_{\max }(d)$ in VT3-1 titanium alloy specimens subject to bending loads. 
The above mentioned behaviour of crack growth rates is assumed to be caused by the size of the plastic zone ahead of the crack tip. It is possible that there took place an inversion of the cracking mechanism, which occurred in components subjected to torsion. What is significant is that the crack growth rate at stress equal to $467 \mathrm{MPa}$ corresponded with fatigue life that was longer than at higher stress values. At stress equal to $467 \mathrm{MPa}$, the fatigue life was $1.67 \cdot 10^{5}$ cycles. Whereas the fatigue life of specimens tested at stress of 525-544 MPa did not exceed $9 \cdot 10^{4}$ cycles (at lower crack growth rates).

The diagrams presented in Fig. 4 constitute an important experimental evidence for the presence of short fatigue cracks in VT3-1 alloy model components subjected to bending loads. The range of short-cracks growth is $150-400 \mu \mathrm{m}$ depending on the value of stress. It exceeds the aforementioned range only at stress equal to $467 \mathrm{MPa}$. The aforementioned range is significantly larger than the range characteristic for cracks that propagate under torsional loads as it results from own extensive research made for VT3-1 titanium alloy. It cannot be excluded that the phenomenon described above is related to a lower stress intensity as well as different material structure and, what is connected with that, different mechanisms which temporarily arrest crack growth. The material of specimens that were subjected to torsional loads showed a very fine-grained structure and the effects of the arrest were restricted to several grains in the structure.

\section{Loading with combined bending and torsional moments, where $M_{t}=M_{b}$}

Under combined bending and torsional loads applied to model fatigue behavior of components, crack initiation took place mostly in the slip bands in $\alpha$-phase grains or at the boundaries of $\alpha$ phase and $\beta$-phase. The contribution of transcrystalline fracture was predominant in relation to grain-boundary cracks. Rectilinear crack paths, which can be observed in Fig. 5, indicate violent nature of crack development in cleavage planes. Crack propagation through the colonies of conveniently located $\alpha$-phase plates of identical crystallographic orientation may be conductive to the aforementioned type of cracking. The moment the crack leaves the colony of $\alpha$-phase plates is oftentimes accompanied by a change of cracking direction, which may be ascribed to the change in crystallographic orientation of contiguous grains or the colonies of $\alpha$-phase plates. Then, the cracks of the lengths of up to a, few dozen micrometers are arrested at the phase boundaries. The intensity of the development of short cracks as well as crack arrest at grain boundaries manifested themselves in the form of fluctuation in crack growth rate, which can be observed in crack growth rate diagrams in Fig. 8.

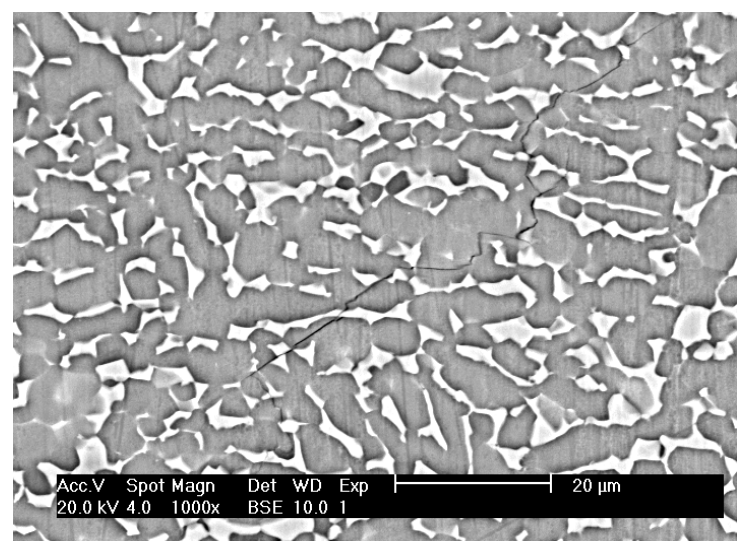

Fig. 5. A short fatigue crack on the surface of the notch bottom in the specimen tested at $S_{e q}=530 \mathrm{MPa}$, recorded after $N_{i}=2,1 \cdot 10^{4}$ load cycles 
Short fatigue cracks initiated from two sources on the surface of the notch bottom in the areas of maximum material effort, in the band that is inclined at an angle of $57^{\circ} \div 60^{\circ}$ to the specimen axis (see Fig. 6). The angle of dominant crack orientation was higher only in the case of specimen tested at $\mathrm{S}_{\mathrm{eq}}=470 \mathrm{MPa}$. In that case, the angle was approximately $70^{\circ}$.

From each source of crack nucleation, there usually propagates one dominant crack. The development of dominant cracks from two sources took place in the same fracture plane, which led to the destruction of the component. The analysis of the angles of the orientation of fracture planes to the specimen axis showed somewhat higher values in relation to the angles of the growth of macrocracks on the surfaces of tested specimens. The angles were of $62^{\circ}$ to $67^{\circ}$ (see Fig. 7). Considering the distribution of stresses at the notch root and the scattering of the results connected with the method for measuring the angles, it is easy to notice that the propagation of dominant cracks took place in the planes approximate to the maximum normal stress planes.



Fig. 6. Fatigue crack in the specimen tested at $S_{\text {eq }}=530 \mathrm{MPa}$ recorded after $N_{i}=3.7 \cdot 10^{4}$ load cycles.
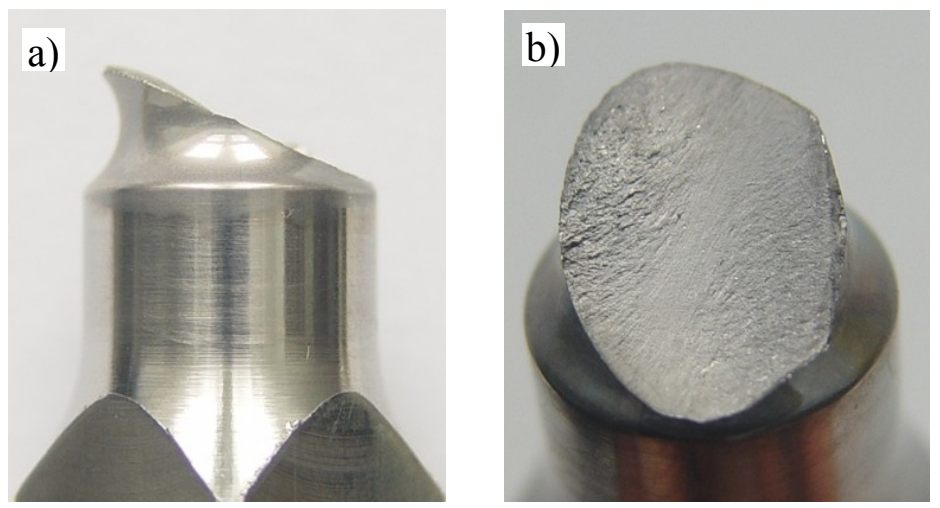

Fig. 7. The images of the fracture of the specimen tested at $S_{e q}=530 \mathrm{MPa}\left(N_{f}=6.2 \cdot 10^{4}\right.$ cycles $)$

The features of cracking discussed above are reflected in the diagrams in Fig. 8. The diagrams illustrate crack growth rates depending on the cycle ratio of the number of current cycles, $\mathrm{N}_{\mathrm{i}}$, to the number of cycles to failure, $\mathrm{N}_{\mathrm{f}}$, (Fig. 8a) and crack growth rates in relation to the lengths of cracks on specimens surfaces (Fig. 8b). Irregularity in the arrangement of measuring points was caused 
by the complex mechanism of crack growth as well as the temporary arrest of cracks at $\alpha$-phase and $\beta$-phase grain boundaries. Under the load that was applied, there appeared short fatigue cracks of the lengths of 50 to $200 \mu \mathrm{m}$, however, short cracks were clear to see only at stress $\mathrm{S}_{\text {eq }}$ $=470 \mathrm{MPa}$. The range of the development of short cracks covers $50 \%$ of the specimen's fatigue life, which is expressed by the ratio $\mathrm{N}_{\mathrm{i}} / \mathrm{N}_{\mathrm{f}}=0.5$. The symbols $\mathrm{v}_{1}$ and $\mathrm{v}_{2}$ in the diagrams indicate the growth rates of two cracks that advanced independently of each other in the notch zone of the same specimen at stress equal to $470 \mathrm{MPa}$. The connection of the two cracks took place just before the specimen was destroyed. A characteristic feature related to the aforementioned cracks is a steep decrease in crack growth rates. From initially high values, crack growth rates dropped by at least two orders of magnitude. It is important to pay attention to the $\mathrm{v}_{2}$ crack, which does not propagate for quite a long period of the fatigue life of the specimen (see Fig. 8a). It cannot be excluded that there occurred a strong arrest of that crack at structural barriers.


Fig. 8. The growth of cracks in VT3-1 titanium alloy specimens subject to combined bending and torsion. The diagrams of crack growth rates depending on the cycle ratio $N_{i} / N_{f}$ (a) and on the length of surface cracks (b)

\section{Loading with combined bending and torsional moments, where $M_{t} / M_{b}=2.25$}

Another stage of the basic research involved loading specimens with combined bending and torsional moments so that there was an equality of torsional and bending stresses at the notch bottom. The stresses were calculated by an elementary method, with taking into consideration stress concentration factors. In that case, the ratio $\mathrm{M}_{\mathrm{t}} / \mathrm{M}_{\mathrm{b}}=2.25$.

An increased contribution of the torsional moment in the abovementioned type of load affected the direction of fatigue crack growth. Macrocracks developed in the band that was inclined at the angle of $44^{\circ} \div 51^{\circ}$ to the specimen axis. An example of a crack developing at the stress $S_{\text {eq }}$ $=538 \mathrm{MPa}$ is presented in Fig. 9. What draws attention is a stepwise crack growth at the initial stage, which is connected with cracking in $\tau_{\max }$ planes. After the initial stage of crack extending, long cracks propagated towards the plane of maximum normal stresses. The angle between the fracture plane and the specimen axis was changing significantly and it ranged from $50^{\circ}$ to $61^{\circ}$. The image of the fatigue zone and the orientation of fracture planes is presented in Fig. 10. Just like previously, the development of dominant cracks took place in planes approximate to the maximum normal stress planes. 
The results of experimental research were used for producing crack growth rate diagrams (see Fig. 11). The symbols $v_{1}$ and $v_{2}$ in the diagrams refer to two cracks growing independently of each other on one side of the notch in a specimen tested at $\mathrm{S}_{\text {eq }}=538 \mathrm{MPa}$. The courses of the diagrams do not differ significantly in relation to the courses of diagrams produced for other load conditions. Irregularities in the arrangement of points noticeable in the diagrams were caused by temporary crack arrests at the boundaries of $\alpha$ - and $\beta$-phases.

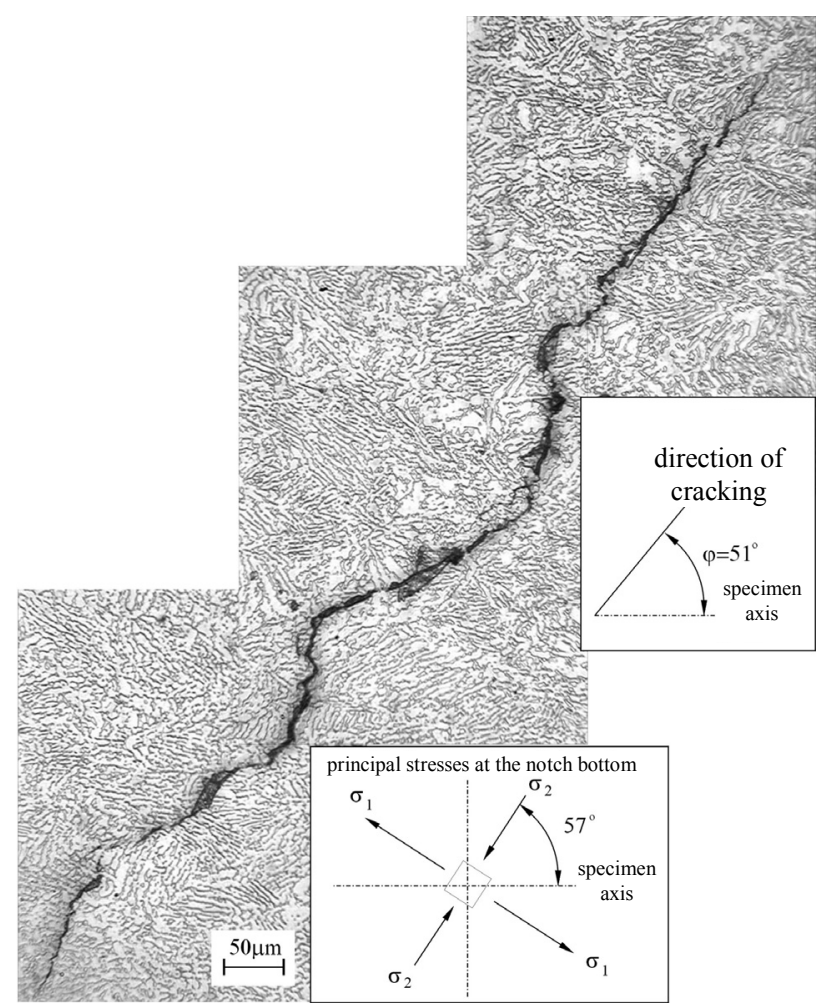

Fig.9. Fatigue crack in the specimen tested at $S_{e q}=538 \mathrm{MPa}$ recorded after $N_{i}=11.5 \cdot 10^{4}$ cycles.
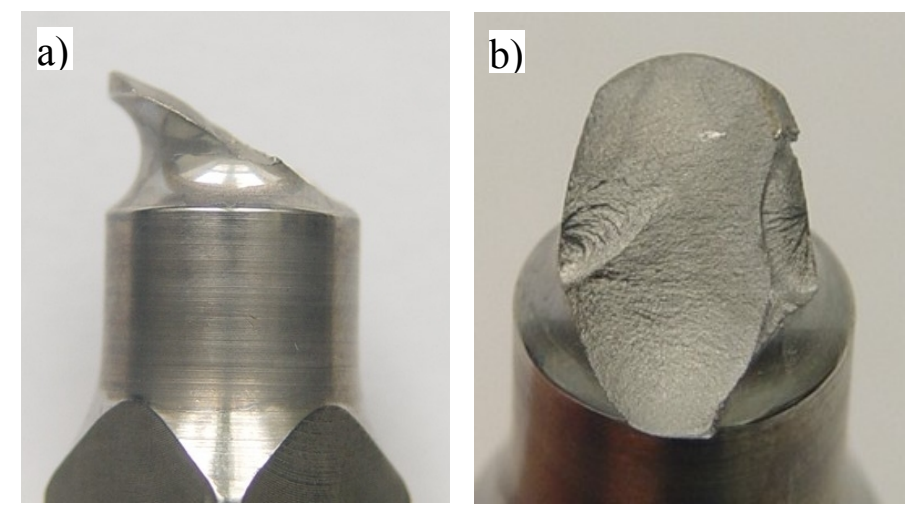

Fig. 10. The image of a fracture in a specimen tested at $S_{e q}=538 \mathrm{MPa}$, where the ratio $M_{t} / M_{b}=2.25\left(N_{f}=16.6 \cdot 10^{4}\right.$ cycles $)$

There was observed the presence of short fatigue cracks, the growth of which occurred with a characteristic decrease in crack growth rates. It is most noticeable in the case of the specimen tested at $\mathrm{S}_{\mathrm{eq}}=516 \mathrm{MPa}$. It should be emphasized that the aforementioned decreases in cracks growth rates are less sharp than those in Fig. 8, which concerned specimens tested at $\mathrm{M}_{\mathrm{t}}=\mathrm{M}_{\mathrm{b}}$. On the whole, it can be stated that the lengths of short cracks are in the range of 50 to $400 \mu \mathrm{m}$ and the 
occurrence of short cracks reaches the ratio $\mathrm{N}_{\mathrm{i}} / \mathrm{N}_{\mathrm{f}}$ of about 0.6 . It is an exceptionally large contribution of short crack growth life in the total fatigue life of tested model components.


Figure 11. Crack growth in VT3-1 titanium alloy specimens subject to combined bending and torsion.

The diagrams of crack growth rates depending on the lengths of surface cracks (a) and the ratio $N_{i} / N_{f}(b)$, where $M_{t} / M_{b}=2.25$.

\section{Loading with combined bending and torsional moments, where $M_{t}=0.5 M_{b}$}

The research on the propagation of cracks in specimens loaded with combined torsion and bending moments, where the moment ratio $\mathrm{M}_{\mathrm{t}} / \mathrm{M}_{\mathrm{b}}$ is 0.5 , was complementary to the basic researches described above, since it was carried out on VT3-1 titanium alloy specimens that came from a different supply. The method for the preparation of the material, the material's mechanical properties and crystallographic microstructure are described in point 2.

The application of a material of somewhat different structure significantly affected the course of fatigue crack growth. A preliminary analysis conducted with the use of a NEOPHOT-2 optical microscope showed that cracks grew in a stepwise manner and they propagated rectilinearly across the colonies of identically oriented $\alpha$-phase plates. The change in the direction of crack propagation most often took place at the boundaries of the colonies. The initial stage of cracking was strongly influenced by the crystallographic orientation of the structure of components. Cracking of a similar nature took place under loading with combined torsional and bending moments, where $\mathrm{M}_{\mathrm{t}} / \mathrm{M}_{\mathrm{b}}=1$. However, the contribution of that type of cracking was significantly smaller than in the situation where $\mathrm{M}_{\mathrm{t}} / \mathrm{M}_{\mathrm{b}}=0.5$. Macroscopic cracks propagated at the angle of $77^{\circ} \div 81^{\circ}$ to the specimen axis. An example of such a crack in a specimen tested at $\mathrm{S}_{\text {eq }}=532 \mathrm{MPa}$ recorded after $\mathrm{N}_{\mathrm{i}}=4.1 \cdot 10^{4}$ load cycles is presented in Fig. 12. The orientation of fracture planes was similar, namely, it was in the range of $72^{\circ}$ to $79^{\circ}$ (see Fig. 13a). Crack growth occurred in the planes approximate to the maximum normal stress plane. Fracture surface with the fatigue zone of a large granulation indicates a violent nature of crack growth (see Fig. 13b).

The change of the cracking mechanism is reflected in crack growth rate diagrams in Fig. 14. No characteristic features of short fatigue cracks were observed. Insignificant fluctuations in crack growth rates were interrelated with the effect of temporary crack arrest at structural barriers. Crack growth rate was increasing rapidly irrespective of the values of stress, in a manner characteristic of long fatigue cracks. 
The mechanism of the crack propagation into components was analyzed on the basis of microfractographic images obtained by means of a PHILIPS XL30 scanning electron microscope. The images of fracture surfaces taken at different depths indicate a rapid advances of fatigue cracks. It is particularly noticeable at the initial stage of cracking, which is documented by images shown in Figs 15a and 15b. Figure 15a illustrates the specimen fatigue fracture surface in the vicinity of the crack source. The image in Fig. $15 \mathrm{~b}$ is a magnified fragment of the area shown in Fig. 15a. The violent nature of cracking manifested itself in the forms of slides on the surface layer, secondary cracks as well as a large contribution of brittle intercrystalline cracking along $\alpha$ phase boundaries. The contribution of brittle cracking decreased with the crack depth. In the central part of the fatigue zone, cracking of a mixed nature was predominant (see Fig. 15c). Brittle cracking was accompanied by the presence of numerous multidirectionally oriented areas covered by plastic fatigue striations, which was observable up to the boundary of the fatigue zone and the residual area. In the residual area, there occurred mostly plastic cracking (see Fig. 15d).

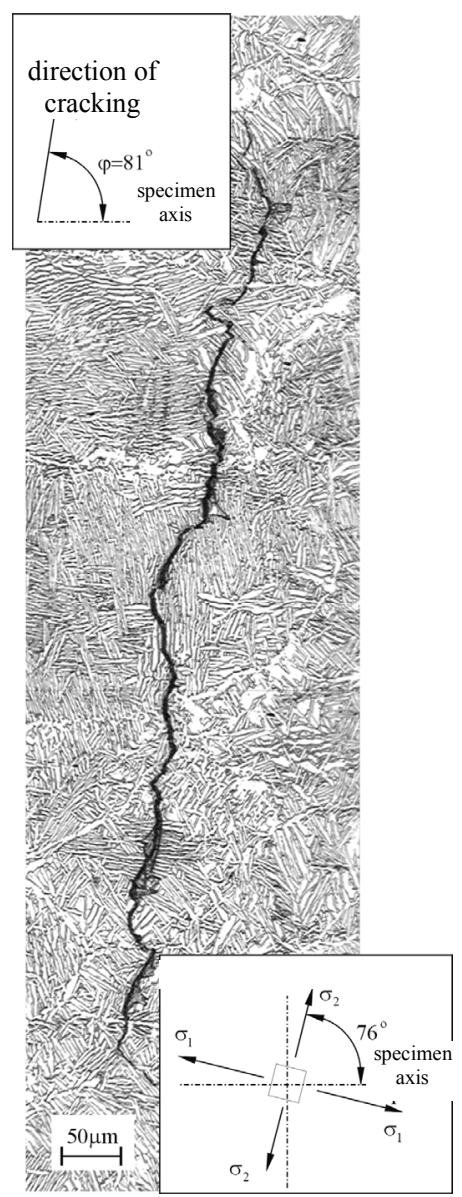

Fig. 12. Fatigue cracking in the specimen tested at $S_{e q}=532 \mathrm{MPa}$ recorded after $N_{i}=4.1 \cdot 10^{4}$ cycles.

The occurrence of the mechanisms of brittle - cleveage cracking and, to some extent, cracking along $\alpha$-phase boundaries in the VT3-1 alloy in the specimen surface layers up to the depth of 100 $-120 \mu \mathrm{m}$, thus, in the range of the development of short fatigue cracks, has been attempted to be attributed to the effect of hydrogen, which is absorbed form the air during lengthy fatigue tests. Hydrogen, which penetrates into the sides of microcracks, settles on the microcrack tip and counteracts the crack tip closing effect. Therefore, the growth rate of short cracks increases, which is observable in crack growth rate diagrams in Fig. 14. 

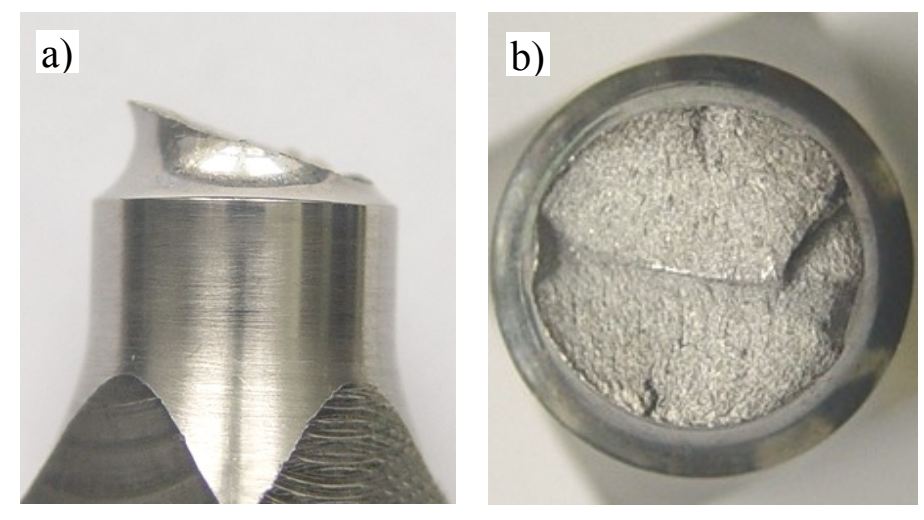

Fig.13. The image of a specimen tested at $S_{e q}=549 \mathrm{MPa}\left(N_{f}=4.9 \cdot 10^{4}\right.$ cycles $)$.
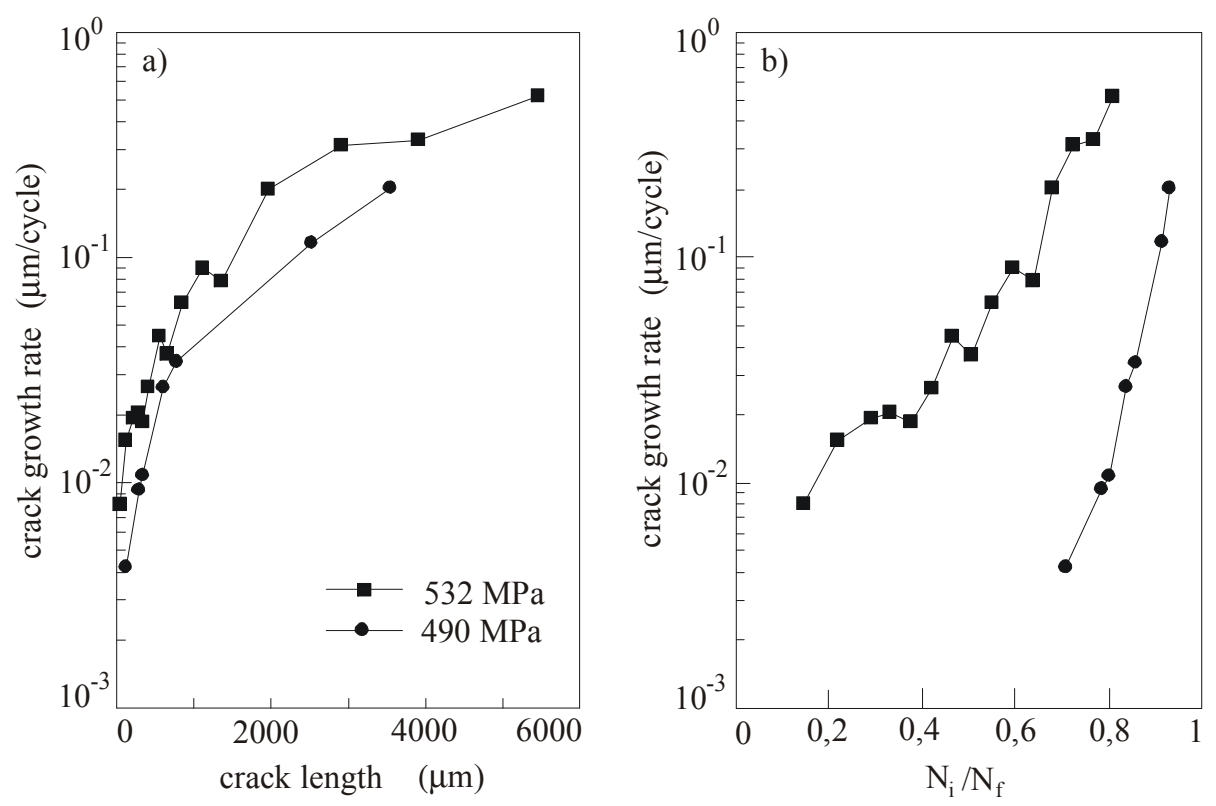

Fig. 14. Crack growth in VT3-1 titanium alloy specimens subject to combined bending and torsion loads. The diagrams of crack growth rates depending on the lengths of surface cracks (a) and the ratio $N_{i} / N_{f}(b)$, where $M_{t} / M_{b}=0.5$

Hydrogen concentration decreases with the crack depth. As a result of that, the contribution of brittle cracking decreases and so does the growth rate in the range of short cracks. The signalled change of the cracking mechanism, which manifested itself in the form of plastic fatigue striations that retarded crack growth, occurred at the depth of about $150 \mu \mathrm{m}$, which was still in the area of short cracks. At a greater depth, one could observe fracture surfaces covered by fatigue striations. Striation spacing was large, which indicated a high growth rate of the crack, which was already a long one. The assumptions were confirmed by examining hydrogen desorption from different parts of specimens (after fatigue test have been conducted) in the function of the time of specimen heating (see Ref. [7]). The highest hydrogen concentration was found in surface layers of specimens in the zone of fissile cracking. Twice lower hydrogen concentration was found in the central part of the fracture, whereas, in the handle part of the specimen, which was far away from the cracking zone, hydrogen concentration was ten times lower. Therefore, it can be stated that an elevated hydrogen concentration, which causes the brittleness of the side layer of a crack surface, is one of the possible causes of a high initial growth rate of short cracks. The above conclusions apply to all load conditions which VT3-1 alloy specimens were subject to. 


\section{Loading with the torsional moment}

The last stage of the experimental research, which concerned the propagation of fatigue cracks in the VT3-1 titanium alloy, was conducted on specimens subjected to torsional moments at an cyclic reversed load $(\mathrm{R}=-1)$. The amplitudes of torsional stress, $\mathrm{S}_{\mathrm{a}, \mathrm{t}}$, calculated with taking into consideration the stress concentration factor $\mathrm{K}_{\tau}$ were being changed in the elastic range from 250 to $500 \mathrm{MPa}$. The specimens of that series were made of a material of somewhat different structure and mechanical properties in comparison to specimens tested under previous load conditions. Detailed information is provided in point 2. The specimens were also of somewhat different dimensions. The main difference was that the notch had a radius of $\rho=4 \mathrm{~mm}$, while under other load conditions, the notch radius was $\rho=3 \mathrm{~mm}$.
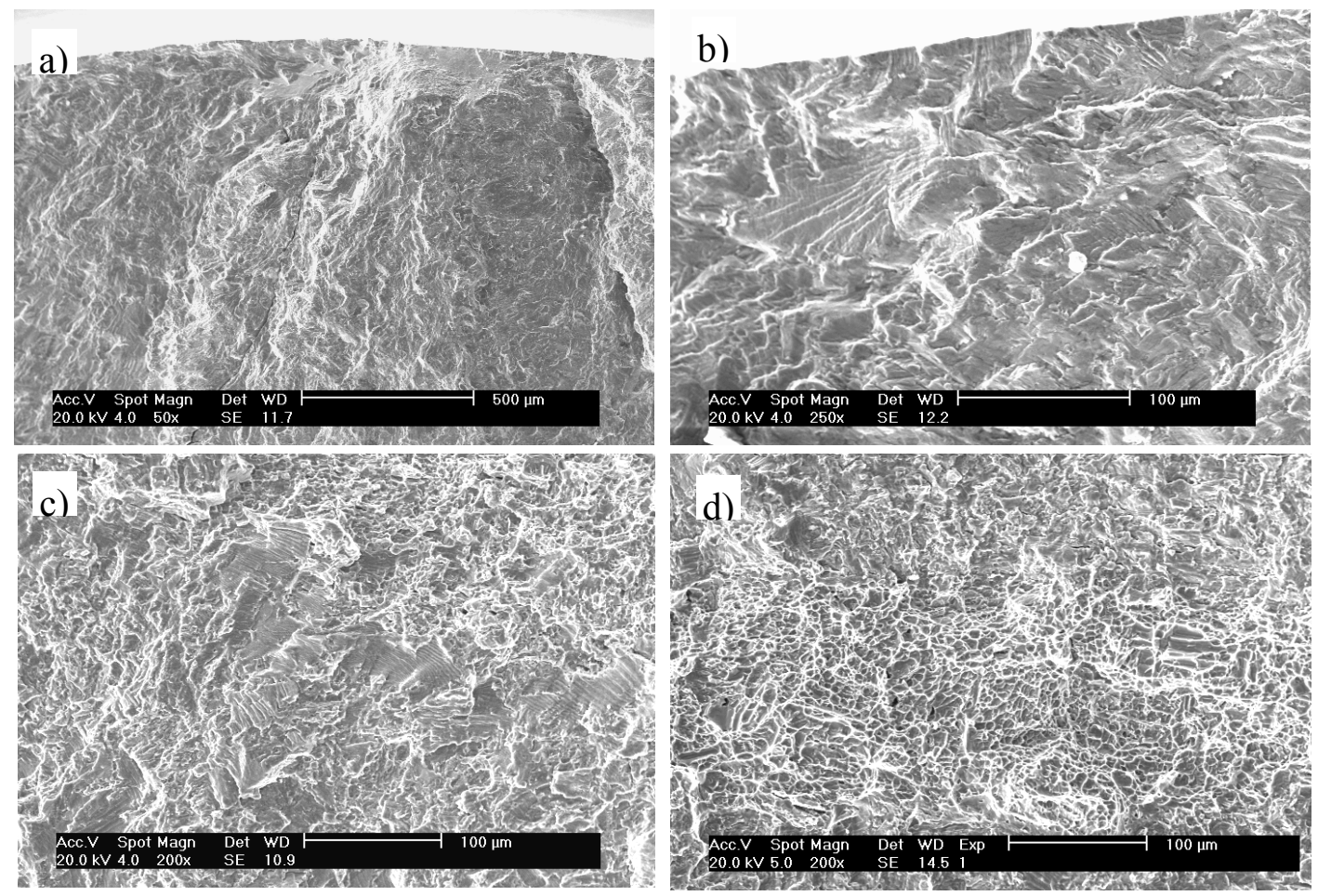

Figure 15. The images of fracture surfaces in the specimen tested at $S_{e q}=549 \mathrm{MPa}\left(\mathrm{N}_{f}=4.9 \cdot 10^{4}\right.$ cycles $)$

In the case of torsion, there was an identical state of stress at each point around the circumference of the notch bottom, which was characterized by the same values of $\sigma_{1}, \sigma_{2}$ and $\tau_{\max }$ components. The state of stress contributed substantially to the complex nature of fatigue crack growth. Two typical mechanisms of crack growth were distinguished.

In specimens tested at high stress values, cracks emerged at many points around the circumference of the notch bottom. The privileged direction of crack propagation was the one that lined up with the specimen axis. After a larger number of load cycles, short cracks propagated also in the direction that was perpendicular to the specimen axis. It follows that they propagated in the planes of maximum shear stresses in both cases. An example of a propagation of such a crack is presented in Fig. 16. The connection of intersecting short cracks, which initiated at many points around the perimeter of the notch bottom, leads to the occurrence of a fracture that has an extensive surface, which can be observed in Fig. 17a. It is characteristic that macrocracks of stepwise nature, which advanced as a result of the connection of short cracks, are located in the planes of the maximum normal stresses (see Fig. 17b). 


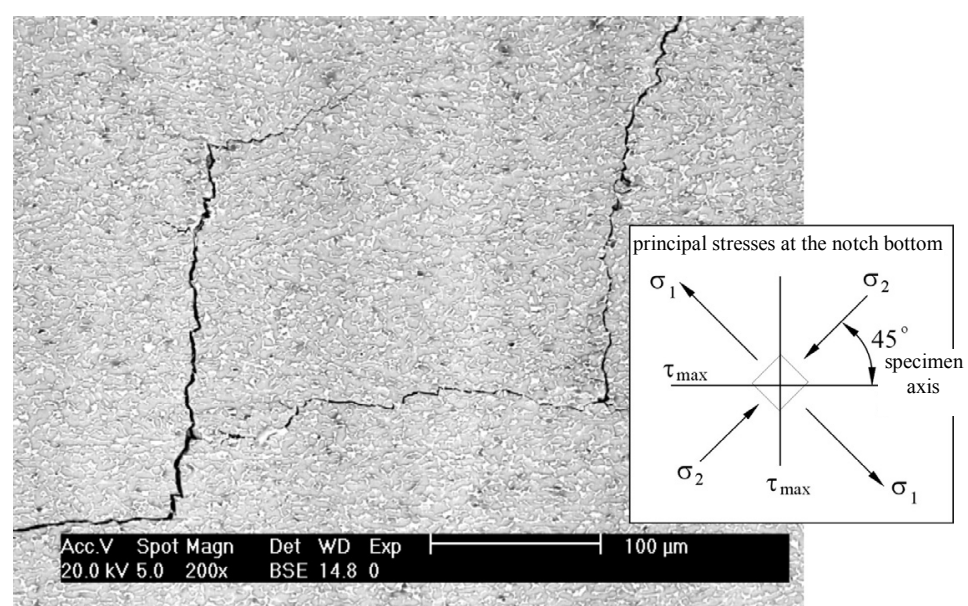

Fig. 16. Short fatigue cracks propagating in the planes of maximum shear stresses.
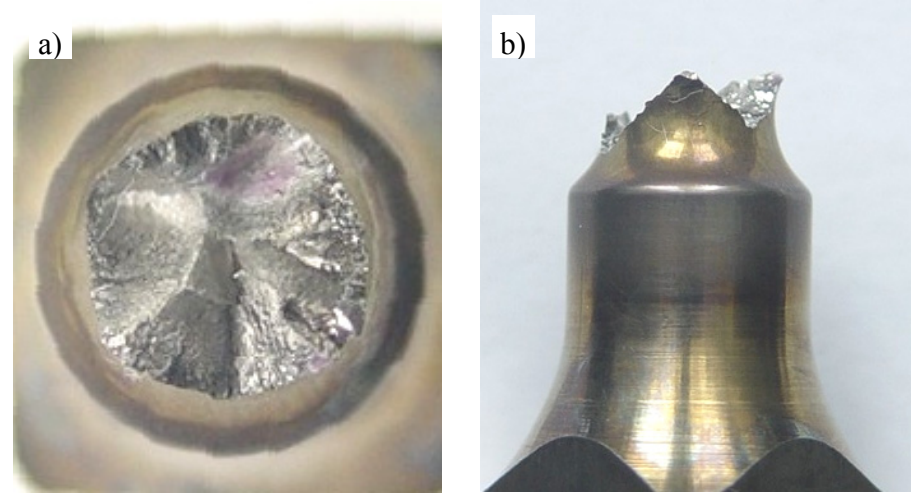

Fig. 17. The image of a fracture in a specimen tested at $S_{a, t}=400 \mathrm{MPa}\left(N_{f}=10^{5}\right.$ cycles $)$
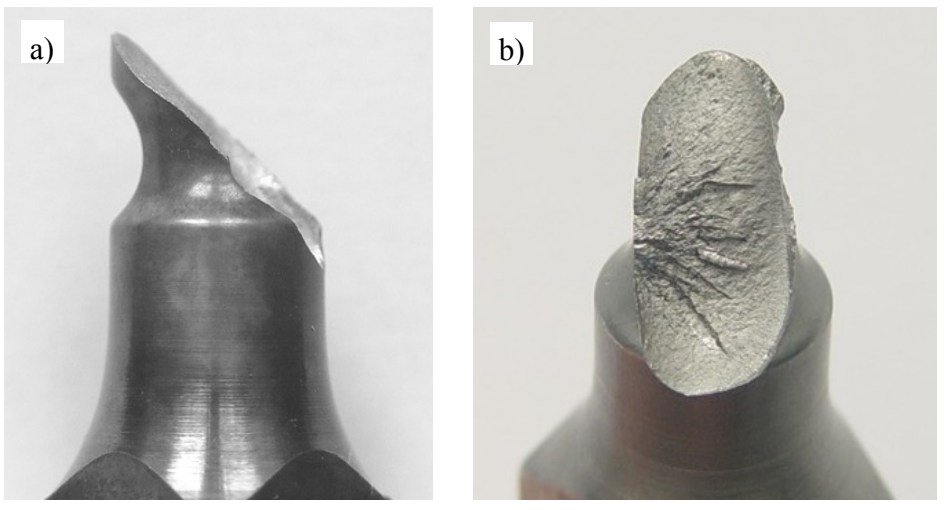

Fig. 18. The image of a fracture in a specimen tested at $S_{a, t}=350 \mathrm{MPa}\left(N_{f}=1.49 \cdot 10^{5}\right.$ cycles $)$

Considering the simultaneous initiation of many cracks at the notch bottom, fatigue crack growth rate ought to be determined from a statistic analysis, which was not yet performed at that stage of research. For that reason, exemplary crack growth rate diagrams are not provided.

Somewhat different images of crack propagation were observable in specimens tested at the stresses lower than $S_{a, t}=350 \mathrm{MPa}$. In a macroscopic sense, cracks propagated at the angle of $45^{\circ}$ to the specimen axis (see Fig. 18a), thus, in the plane of maximum normal stresses. What deserves attention is the fact that the dominant crack propagated from only one source at the notch bottom (see Fig. 18b). 


\section{SUMMARY}

There was investigated the effect of a complex state of stress on the propagation of both short and long fatigue cracks as well as on the orientation of the cracking plane in VT3-1 titanium alloy components with circumferential notches, at different ratios of the torsional to the bending moments. The presence of a range of the growth of short fatigue cracks at a limited range of stresses was noticed. Characteristic behaviour of short fatigue cracks initiated on an circumference notch surface was observed. A characteristic feature was the irregularity in the propagation of short cracks, which was caused by the strong influence of the material structure. The aforementioned irregularities in crack propagation were reflected in crack growth rate diagrams. A high initial growth rate of short cracks in specimens was attributed to the possible effect of atmospheric hydrogen that penetrated the sides of cracks during fatigue tests. The depth of hydrogen penetration corresponded with the depth of the occurrence of brittle cracking, fissile cracking and cracking along $\alpha$-phase boundaries in the VT3-1 alloy. The range of the propagation of short surface cracks under bending loads was from 150 to $400 \mu \mathrm{m}$, whereas under combined bending and torsional loads it ranged from 50 to $400 \mu \mathrm{m}$. The range of the occurrence of short cracks in the VT3-1 titanium alloy may be even up to $60 \%$ of a component fatigue life. The features characteristic of the analyzed cracks were not noticed at high stresses. A significant influence of the VT3-1 alloy structure on the propagation of cracks was observed. In the case of an alloy of lamelar structure tested at $\mathrm{M}_{\mathrm{t}}=0.5 \mathrm{M}_{\mathrm{b}}$, no signs of short fatigue cracks were found in any stress range. The angle of the inclination of a fracture plane to the specimen axis was changing depending on load conditions. The orientation of these planes was approximate to the orientation of the planes of the principal stresses at the point of maximum material effort at the notch bottom. At combined bending and torsional moments, where $\mathrm{M}_{\mathrm{t}}=0.5 \mathrm{M}_{\mathrm{b}}$, the angle was in the range of $72^{\circ} \div 79^{\circ}$. At $\mathrm{M}_{\mathrm{t}}=\mathrm{M}_{\mathrm{b}}$, the angle of the inclination of the planes of specimen fractures was smaller, namely $62^{\circ} \div 67^{\circ}$. Increasing the contribution of the torsional moment in relation to the bending moment up to the ratio $\mathrm{M}_{\mathrm{t}} / \mathrm{M}_{\mathrm{b}}=2.25$ resulted in the situation where the planes of specimen fractures were inclined to specimen axes at the angles of $50^{\circ}$ to $61^{\circ}$. Research results constitute an experimental base for an analytical description of the fatigue crack growth rates of components, in terms of short and long cracks, as well as predicting the orientation of the entire crack plane of a component under complex loads.

\section{REFERENCES:}

[1] Kocanda, D., Kocanda, S., \& Mierzyński, J. (2000). Fatigue cracks in the VT3-1 titanium alloy notched model components [in Polish]. Military University of Technology WAT Bulletin, 5, $35-57$.

[2] Mierzyński, J. (2004) Fatigue crack growth in the VT3-1 titanium alloy under complex stress state [in Polish]. Ph. D. Thesis, Military University of Technology WAT.

[3] Kocanda, D. (1996). The analysis of short crack growth [in Polish]. Military University of Technology WAT.

[4] Kocanda, D. (2000). The research into short cracks. In Szala J. (Eds.), Part II. Monographies. Experimental methods in the fatigue of materials and structures. Basic investigations (pp. 59148). Bydgoszcz: ATR.

[5] Kocanda, D., \& Kocanda, S. (1999). Initiation and short fatigue crack propagation in 45 steel [in Polish]. Mechanical Review. 8, 5-9.

[6] Kocanda, D. (1996). Probabilistic description of fatigue short crack growth in normalized and laser hardened 0,45 \% C steel elements. The Archive of Mechanical Engineering, 2(3), 2-17. 
[7] Kocańda, D., Kocańda, S., Łunarska, E., \& Mierzyński, J. (2005). Possibility of hydrogenassisted propagation of short fatigue crack growth in WT3-1 titanium alloy. Physico Chemical Mechanics of Materials, 3, 25-28. 